\title{
Estabilidade de Agregados de Latossolos em Floresta Estacional Semidecidual, Paraná, Sul do Brasil
}

\author{
Stability Aggregates of Oxysols in Seasonal Semideciduos Forests, Paraná, \\ Southern Brazil
}

\section{Estabilidad de los Agregados de Oxisoles en Bosque Estacional Semideciduo, Paraná, Sur de Brasil}

\author{
Laine Milene Caraminan ${ }^{1}$ \\ https://orcid.org/0000-0001-8239-2578 \\ Jaqueline Gorish Wilkomm Fruet ${ }^{2}$ \\ https://orcid.org/0000-0002-9844-8393 \\ Nelson Vicente Lovatto Gasparetto ${ }^{3}$ \\ https://orcid.org/0000-0003-1293-4110
}

\begin{abstract}
RESUMO: O presente trabalho teve por objetivo quantificar a estabilidade e correlacionar as classes de agregados com os valores de argila e carbono orgânico em dois perfis de Latossolos com texturas diferentes, localizados em áreas remanescentes da Floresta Estacional Semidecidual (FES), no estado do Paraná, sul do Brasil. Foram considerados para a análise o Centro das Classes (CMM) e o Diâmetro Médio Ponderado (DMP). O Latossolo Bruno textura média (LB) apresenta agregados com tamanhos $>3 \mathrm{~mm}$ nos horizontes superficiais $(A$ e $A B$ ) com redução do tamanho dos agregados em profundidade. $O$ Latossolo Vermelho textura muito argilosa (LV) apresenta predominantemente agregados $>3 \mathrm{~mm}$. Em ambos os perfis foi destacado a classe dos macroagregados, entretanto, o LB apresentou incremento dos microagregados em profundidade e, também, os menores valores de DMP quando comparado com o LV. As correlações indicaram que no LB a argila está contribuindo para a agregação dos microagregados, enquanto que o carbono orgânico pouco contribui com os macroagregados. Para o LV, o carbono orgânico apresentou correlação com os macroagregados, ao ponto que a argila contribuiu pouco para os microagregados. Os resultados sugerem dinâmicas de agregação diferentes para cada solo, possivelmente pela constituição textural de cada perfil.
\end{abstract}

PALAVRAS-CHAVE: Classe de agregados. Argila. Carbono orgânico.

\footnotetext{
1 Mestranda pelo Programa de Pós-Graduação em Geografia (PGE) da Universidade Estadual de Maringá. E-mail: caraminanlaine@gmail.com.

2 Doutoranda pelo Programa de Pós-Graduação em Geografia (PGE) da Universidade Estadual de Maringá. E-mail: jaquelinefruet@yahoo.com.br.

3 Doutorado em Geociências (Geoquímica e Geotectônica) pela Universidade de São Paulo. Professor do Departamento de Geografia da Universidade Estadual de Maringá. E-mail: nvlgasparetto@uem.br.
} 
ABSTRACT: The objective of this work was to quantify the stability and correlate the aggregate classes with the values of clay and organic carbon in two oxisols profiles with different textures and located in remaining areas of the Seasonal Semideciduous Forest (SSF) in the state of Paraná, southern Brazil. The procedures of Salton et al. (2017) were followed considering the Center of the Classes (CMM) and the Weighted Average Diameter (WAP). The Oxisol Medium Texture (LB) presents aggregates with sizes $>3 \mathrm{~mm}$ in the superficial horizons $(A, A B)$ with a decrease in the size of the aggregates in depth. Oxysol Very Clayey Texture (LV) has predominantly aggregates $>3 \mathrm{~mm}$. In both profiles there was a predominance of the macroaggregate class, however, the $L B$ showed an increase in the microaggregates in depth and also the lowest DMP values when compared to the $L V$. The correlations indicated that in $L B$, the clay is contributing to the aggregation of microaggregates, while carbon contributes little to macroaggregates. For $L V$, carbon was correlated with macroaggregates, to the point that clay contributes a little to the aggregation of microaggregates. The results suggest different aggregation dynamics for each soil, possibly due to the textural constitution of each profile.

KEYWORDS: Class of aggregates. Clay. Organic carbon.

RESUMEN: Este estudio tuvo como objetivo cuantificar la estabilidad y correlacionar las clases de agregados con los valores de arcilla y carbono orgánico en dos perfiles de Oxisoles con diferentes texturas y ubicados en las áreas restantes del Bosque Semideciduo Estacional (BSF) en el estado de Paraná, sur de Brasil. Fueron considerados para el análisis el Centro de las Clases (CMM) y el Diámetro Medio Ponderado (DMP). El Oxisol Bruno textura media (LB) presenta agregados con tamaños $>3 \mathrm{~mm}$ en los horizontes superficiales $(A, A B)$ con una disminución en el tamaño de los agregados en profundidad. El Oxisol rojo textura muy arcillosa (LV) tiene predominantemente agregados> $3 \mathrm{~mm}$. En ambos perfiles hubo un predominio de la clase de macroagregados, sin embargo, el LB mostró un aumento en la profundidad de los microagregados y también los valores más bajos de DMP en comparación con el LV. Las correlaciones indicaron que en LB, la arcilla está contribuyendo a la agregación de microagregados, mientras que el carbono orgánico contribuye poco a los macroagregados. Para LV, el carbono orgánico e correlacionó con macroagregados, hasta el punto de que la arcilla contribuye poco a la agregación de microagregados. Los resultados sugieren diferentes dinámicas de agregación para cada suelo, posiblemente debido a la constitución textural de cada perfil.

PALABRAS CLAVE: Clase de agregados. Arcilla. Carbón orgânico.

\section{INTRODUÇÃO}

A física do solo busca estudar os atributos físicos que compõem os solos e seus processos, incluindo a mensuração e a predição sobre os sistemas naturais e antrópicos a partir das formas, relações e mudanças dos componentes dos solos em suas múltiplas fases (LAL; SHUKLA, 2004). A física do solo dispõe de atributos que estão relacionadas à cor, textura, estrutura, densidade, porosidade, umidade dos solos e outros.

A porção sólida dos solos é composta por materiais inorgânicos (minerais) e orgânicos em seus vários estágios de alteração. Para as partículas que compõem a fração inorgânica dos solos, consideram-se as areias, siltes e argilas e cada uma dessas frações é responsável por determinadas propriedades dos solos (SCHAETZL; ANDERSON, 2005), bem como as características texturais. Neste caso, além de a textura do solo ser considerada um atributo estático do sistema pedológico (CHESWORTH, 2008) ela também 
é frequentemente associada à formação de agregados. A fração orgânica dos solos, assim como a inorgânica, contribui diretamente para a agregação dos solos, isso porque os agregados existentes nos solos são os resultados das interações entre as fases sólidas e liquidas a partir do rearranjo, floculação e cimentação das partículas (BRONICK; LAL, 2005).

A agregação das partículas é a base da estrutura do solo. Nas palavras de White (2006) a estrutura pode ser entendida como o arranjo, o tamanho e a forma das partículas (areia, silte, argila e matéria orgânica) em agregados. Portanto, por meio do tamanho (pequeno, médio e grande), grau de desenvolvimento (fraco, moderado e forte) e forma (laminar, prismático, colunar, blocos e granular) dos agregados é realizada a identificação morfológica estrutural do solo (LEPSCH, 2011). Em consonância, os espaços vazios ou porosos que separam as partículas nos agregados desempenham papel significativo na estabilidade dos agregados e consequentemente, na qualidade desses sistemas (MENON et al., 2020). Nesse sentido, tais características podem ser observadas em campo (macroestruturas) ou em laboratório (microestruturas) a partir de técnicas analíticas.

Como a estrutura do solo é um atributo dinâmico que pode ser alterado ao longo do tempo (CHESWORTH, 2008; TABOADA et al., 2004) de acordo com as condições naturais do ambiente ou pela pressão das atividades antrópicas, bem como o revolvimento, adição de produtos químicos, irrigação, drenagem, manejo e práticas conservacionistas, é imprescindível aferir sobre a estrutura e estabilidade de agregados nos solos. Diversos trabalhos têm corroborado com o intuito de avaliar a estabilidade dos agregados em diferentes sistemas de uso e manejo, a partir da influência do carbono orgânico e da fração argila (CASTRO FILHO; MUZILLI; PODANOSCHI, 1998; CRUZ et al., 2003; FERREIRA et al., 2007; SALTON et al., 2008).

A estabilidade dos agregados é entendida como um indicador da qualidade física do solo, pois é propensa a alterações condicionadas pelo uso e manejo adotados (FILIZOLA e BARRETO LUIZ, 2018) e mantê-la é essencial para minimizar as perdas de solos por erosão (ZENG et al., 2018) que se refletem em impactos nos aspectos físicos e antrópicos do geossistema, como a diminuição da qualidade dos recursos naturais e a produtividade agrícola. Nessa perspectiva, estudos têm sido realizados para evidenciar e relacionar a variação da estabilidade dos agregados com diferentes classes de solos (ALMEIDA et al., 2014; FERREIRA et al., 2007) e sua vulnerabilidade à erosão (SILVA; MIELNICZUK,1998; TERASSI; SILVEIRA; BONIFÁCIO, 2014). Neste contexto, o presente trabalho tem por objetivo avaliar a estabilidade de agregados a partir dos valores de argila e carbono orgânico em dois perfis de Latossolos com texturas diferentes, ambos localizados em áreas remanescentes da Floresta Estacional Semidecidual (FES) no estado do Paraná, sul do Brasil. 


\section{MATERIAIS E MÉTODOS}

\section{Localização e Caracterização das Áreas de Estudo}

O Latossolo Bruno textura média (LB) está localizado no município de Santa Fé, entre as coordenadas $23^{\circ} 07^{\prime \prime} 49^{\prime} \mathrm{S}$ e $51^{\circ} 51^{\prime} 37^{\prime \prime} \mathrm{O}$ (Figura 1). O Latossolo Vermelho textura muito argilosa (LV) localiza-se no município de Jardim Alegre, nas coordenadas 249'58" S e $51^{\circ} 37^{\prime} 47^{\prime \prime}$ O. Ambos os perfis estão localizados no estado do Paraná, sul do Brasil.

Figura 1 - Localização dos perfis dos Latossolos

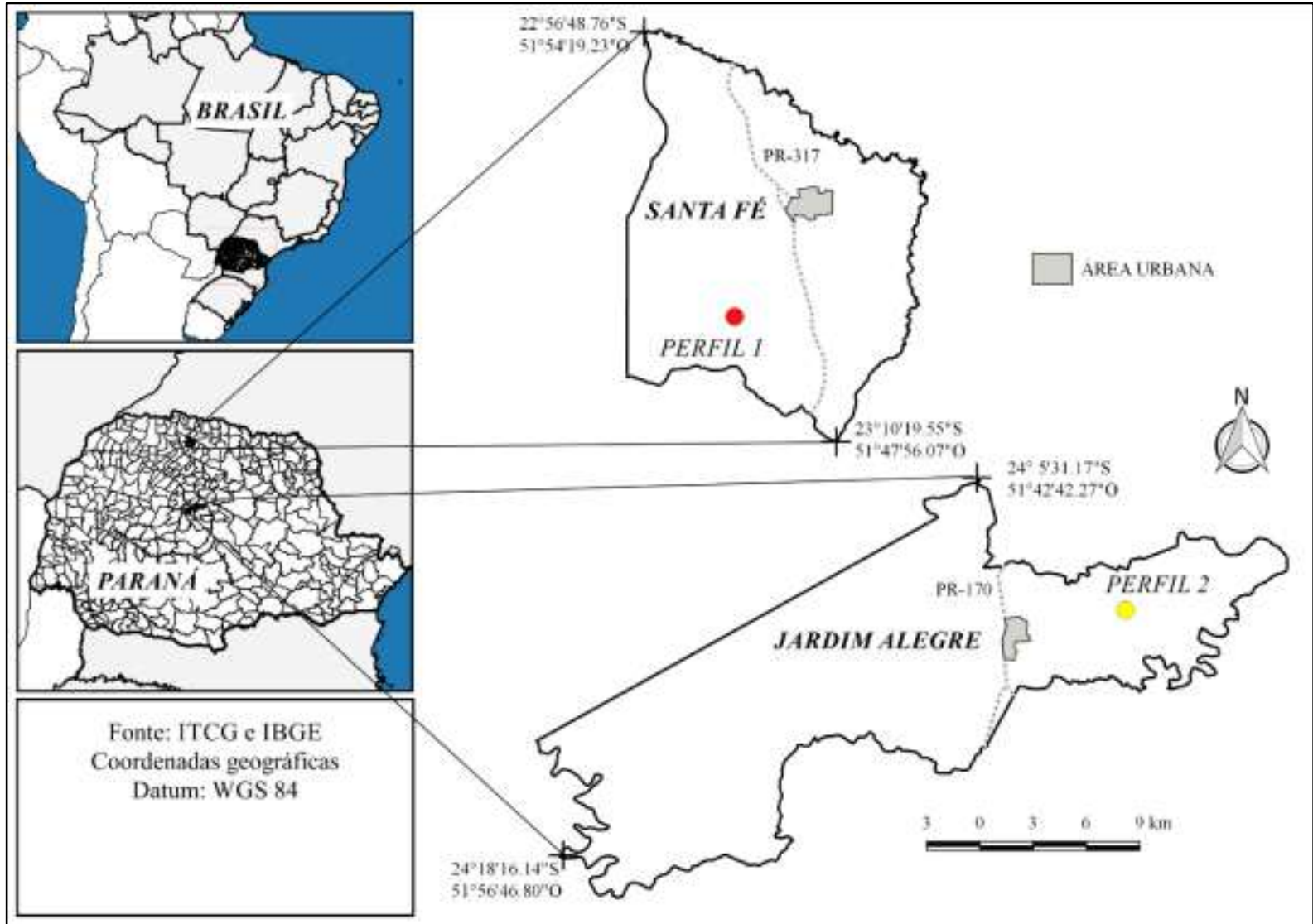

Fonte: Caraminan et al. (2019).

Os perfis pedológicos estão localizados na Bacia Sedimentar do Paraná (BSP). No entanto, o LB é proveniente do intemperismo das rochas da Formação Caiuá (MINEROPAR, 2001). Essas possuem textura composta por frações de areias muito fina a média, grãos com boa esfericidade e cobertos por película ferruginosa, subarredondados, em geral pouco argilosos, podendo apresentar na porção basal, em contato com a Formação Serra Geral, arenitos sílticos (SILVA; KIANG; CHANG, 2005). Quando alteradas, essas rochas dão origem a solos de textura média e arenosa. O quartzo é o mineral predominante nesses 
solos, associado com um plasma constituído por caulinita pobremente cristalizada e óxidos e hidróxidos de ferro (GASPARETTO, 1999).

O LV é formado a partir da intempérie das rochas ígneas da Formação Serra Geral, essas são compostas por basaltos, andesi-basaltos e andesitos de afanidade toleítica, constituídos por plagioclásios, piroxênios, olivina, quartzo, magnetita e apatita. Além disso, podem apresentar coloração cinza-escuro, com estrutura maciça ou vesiculares, subfaneríticos de granulação variando entre média e densa (NARDY et al., 2002). Quando alterada, as rochas dão origem a solos predominantemente siltosos, argilosos e muito argilosos, constituídos por minerais alterados ou em fase de alteração.

O clima que ocorre em Santa Fé, segundo os parâmetros previstos na classificação climática de Köppen, é o Tropical com inverno seco (Ama), com temperatura do mês mais frio acima dos $18^{\circ} \mathrm{C}$ e do mês mais quente acima dos $22^{\circ} \mathrm{C}$ (TERASSI; SILVEIRA, 2013). Em Jardim Alegre, o clima moderno ocorrente é o Cfa (subtropical quente). Este clima é caracterizado por apresentar verões quentes e estação seca não definida. A temperatura média no mês mais quente é superior a $22^{\circ} \mathrm{C}$. As chuvas são mais frequentes nos meses mais quentes e, para o período mais seco, a precipitação é superior a 30 milímetros mensais (LARACH et al., 1984). Essa classificação climática é típica de altitudes inferiores a 900 metros e, para a estação do inverno, há a presença de geadas e temperaturas inferiores a $18^{\circ} \mathrm{C}$.

O LB está inserido no Planalto de Maringá que apresenta baixa dissecação, com topos alongados e aplainados, vertentes convexas e vales em "V" (MINEROPAR, 2006). Na área onde está localizado este perfil pedológico, predominam as cotas altimétricas de 500 a 550 metros, com vertentes alongadas ( $\cong 1,5$ quilômetros de extensão) e topos aplainados, com predomínio de declividades entre 0 e $3 \%$. O LV é encontrado no Planalto de Pitanga/lvaiporã que possui dissecação média, com topos alongados, vertentes convexas e vales em "V" (MINEROPAR, 2006). A altitude da área de coleta está situada entre 600 e 650 metros. A declividade é marcada pelos valores de 0 a $8 \%$, apresentando topos aplainados e vertentes com extensão entre 0,7 e um quilômetro.

Os perfis estão sob a ocorrência da Floresta Estacional Semidecidual (FES), contudo o LB está situado na FES submontana, enquanto que o LV está localizado na FES montana, transicionando paulatinamente ao sul com a Floresta Ombrófila Mista (FOM). A classificação submontana e montana da FES refere-se à altitude em que essas formações vegetais são encontradas. Sendo assim, a submontana é encontra entre 50 e 500 metros de altitude enquanto que a montana é recorrente entre 500 e 1500 metros de altitude (IBGE, 2012).

Fisionomicamente, estas formações são densas, com porte de cerca de 30 metros e indivíduos emergentes que podem alcançar mais de 40 metros de altura e diâmetro entre dois e três metros (COUTINHO, 2016) e são caracterizadas por apresentar repouso 
fisiológico e queda parcial da folhagem nos períodos secos (geralmente no inverno), sendo que entre 20 e $50 \%$ das espécies são caducifólias, ou seja, perdem suas folhas nos períodos de estiagem (IBGE, 2012).

\section{PROCEDIMENTOS METODOLÓGICOS}

Foram abertas duas trincheiras e realizada a descrição macromorfológica dos horizontes (cor, textura, estrutura, consistência e transição de horizontes) do LB (Santa Fé) e do LV (Jardim Alegre) de acordo com o Manual de descrição e coleta de solo no campo (SANTOS et al., 2015) entre os anos de 2017 e 2018. Também foi realizada a análise granulométrica desses perfis. Ambas são encontradas em Caraminan et al. (2019).

De maneira geral, o LB é constituído predominantemente pela fração areia, com valores que variam entre $844,8 \mathrm{~g} / \mathrm{kg}^{-1}$ em superfície (horizonte A) e $769,3 \mathrm{~g} / \mathrm{kg}^{-1}$ em profundidade (horizonte Bw2). As demais frações tiveram pouca expressividade ao longo do perfil. Já o LV é composto pela fração argila, em que os valores máximos e mínimos estão entre 689,4 e $681 \mathrm{~g} / \mathrm{kg}^{-1}$, para os horizontes A e Bw3, respectivamente. Valores entre 298,6 e $304,8 \mathrm{~g} / \mathrm{kg}^{-1}$ foram encontrados para a fração silte. A fração areia teve pouca expressão no perfil (CARAMINAN et al., 2019).

A determinação da estabilidade de agregados via seca foi com base nos procedimentos propostos por Salton et al. (2017), com adaptações que seguem descritas: foram utilizadas 100 gramas de cada amostra indeformada de solo e tamisadas em peneira de 8 milímetros de malha. As amostras foram peneiradas em um conjunto de peneiras com abertura de $4-2-1-0,5$ e 0,25 milímetros e 20 centímetros de diâmetro, durante 15 minutos em um agitador mecânico, de 46 oscilações. Após a agitação, os agregados retidos em cada peneira foram transferidos para beckers enumerados e de peso conhecido e levados à estufa $\left(105^{\circ} \mathrm{C}\right)$ durante 12 horas. Posteriormente, os beckers com as amostras de solos foram levados ao dessecador e pesados. Efetivaram-se cinco repetições para cada amostra de solo, considerando os horizontes de cada perfil. Os valores considerados nos resultados são referentes ao Centro da Classe (CMM) dos agregados.

O cálculo do Diâmetro Médio Ponderado dos agregados (DMP) foi realizado a partir da Equação 1.

$$
\mathrm{DMP}=\Sigma(\mathrm{CMM} \times \mathrm{P})
$$

O CMM é o Centro das Classes de tamanho dos agregados e P é a proporção do peso de cada fração de agregados em relação ao peso da amostra. 
O carbono orgânico foi obtido através do método Walkley-Black, por via indireta a partir da oxidação do carbono orgânico do solo com a solução de dicromato de potássio em presença de ácido sulfúrico (CAMARGO, 1986). Para tanto, foi utilizado $1 \mathrm{~mL}$ de terra fina seca ao ar (TFSA) em erlenmeyer de $250 \mathrm{~mL}$ e adicionado $10 \mathrm{~mL}$ de solução de $\mathrm{K}_{2} \mathrm{Cr}_{2} \mathrm{O}_{7} 1 \mathrm{~N}$ e $10 \mathrm{~mL}$ de $\mathrm{H}_{2} \mathrm{SO}_{4}$ concentrado. Após 30 minutos, adicionou-se $50 \mathrm{~mL}$ de água destilada, $3 \mathrm{~mL}$ de ácido ortofosfórico concentrado e três gotas de difenilamina 1\% (indicador). Procedeu-se a titulação com a solução de sulfato ferroso $\left(\mathrm{FeSO}_{4 \cdot 7} \mathrm{H}_{2} \mathrm{O}\right) 1 \mathrm{~N}$ até o ponto de viragem, onde foi anotado a quantidade de $\mathrm{FeSO}_{4}$ utilizado. Também foi realizada uma prova em branco. Para a obtenção do valor de carbono orgânico, foi utilizado o seguinte cálculo (Equação 2).

$$
\mathrm{C}=\mathrm{Ab}-\mathrm{A} \text { * fator } \mathrm{FeSO}_{4}{ }^{*} 3,896 / \mathrm{mL} \text { de solo }
$$

Onde C é o carbono; Ab é o volume do sulfato ferroso gasto na amostra em branco e A é o volume de sulfato ferroso gasto na amostra; fator $\mathrm{FeSO}_{4}$ foi aproximado para 10 e a $\mathrm{mL}$ de solo é o volume da TFSA utilizada.

Os resultados obtidos com a estabilidade de agregados (CMM) foram plotados em gráficos de dispersão juntamente com as variáveis "argila" e "carbono orgânico", conforme a Tabela 1.

Tabela 1 - Valores de argila, carbono orgânico, macro e microagregados dos Latossolos

\begin{tabular}{|c|c|c|c|c|}
\hline Hor. & $\begin{array}{c}\text { Argila }\left(\mathrm{g} / \mathrm{kg}^{-1}\right) \\
\text { (Caraminan et al., } \\
\text { 2019) }\end{array}$ & $\begin{array}{l}\text { Carbono orgânico } \\
\left(\mathrm{g} / \mathrm{dm}^{-3}\right)\end{array}$ & Macroagregados (\%) & Microagregados (\%) \\
\hline \multicolumn{5}{|c|}{ Latossolo Bruno textura média (LB) } \\
\hline A & 114,2 & 12,47 & 71,51 & 28,48 \\
\hline $\mathrm{AB}$ & 120,7 & 6,23 & 74,57 & 25,43 \\
\hline Bw1 & 173,7 & 3,89 & 60,12 & 40,88 \\
\hline Bw2 & 190,5 & 3,12 & 52,61 & 47,39 \\
\hline \multicolumn{5}{|c|}{ Latossolo Vermelho textura muito argilosa (LV) } \\
\hline A & 681,0 & 26,49 & 97,03 & 2,98 \\
\hline $\mathrm{AB}$ & 685,1 & 13,25 & 93,83 & 6,16 \\
\hline Bw1 & 681,1 & 10,13 & 94,09 & 5,9 \\
\hline Bw2 & 687,0 & 6,62 & 92,39 & 7,62 \\
\hline Bw3 & 689,4 & 4,68 & 92,28 & 7,72 \\
\hline
\end{tabular}

Fonte: elaboração dos autores. 


\section{RESULTADOS}

\section{Distribuição das Classes de Agregados nos Latossolos}

Os resultados da estabilidade de agregados permitiram identificar e avaliar a agregação dos horizontes de Latossolos com diferentes texturas, em áreas remanescentes da FES e sua relação com os teores de argila e carbono orgânico.

O LB com estrutura grau fraco a moderado, tamanho pequeno e tipo granular (CARAMINAN et al., 2019) é constituído em seu horizonte A (superficial) predominantemente por agregados com tamanhos de 6 e 3 milímetros. Essas classes juntas são responsáveis por $51,03 \%$ dos agregados desse horizonte. As demais classes contribuem com 48,97\% para o horizonte $A$, sendo a classe 0,125 milímetros a menos expressiva. Em profundidade, esses valores tiveram um decréscimo considerável, com 16,49\% para o horizonte AB, 9,99\% para o Bw1 e 17,05\% Bw2 (Figura 2).

Figura 2 - Distribuição das classes de agregados no Latossolo Bruno textura média (LB)

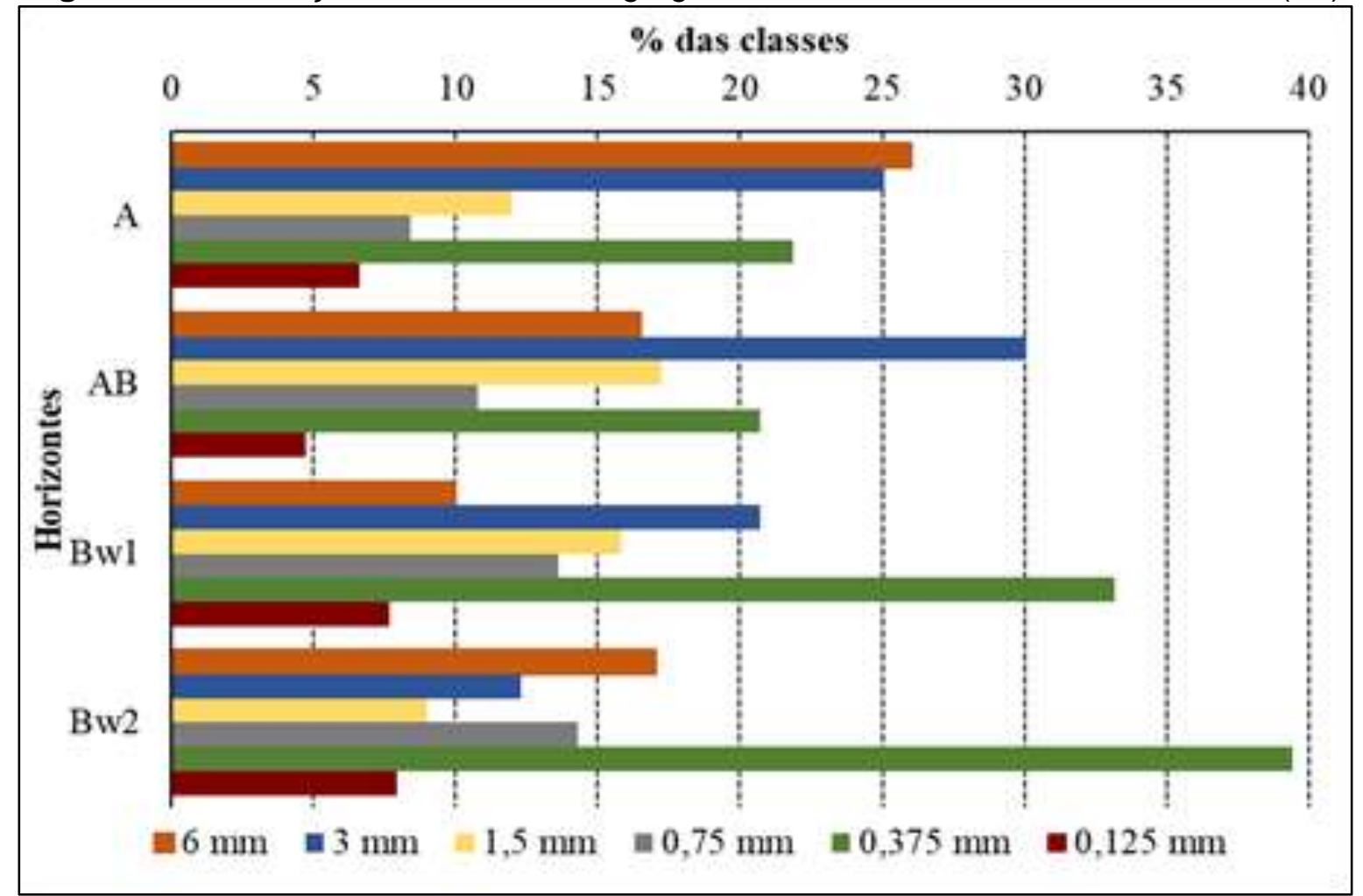

Fonte: os autores.

O horizonte AB apresentou-se constituído em até 30,06\% por agregados com tamanho de 3 milímetros, seguido pela classe de 0,375 milímetros com 20,7\%, que juntas, tiveram maior expressividade nesse horizonte, totalizando $51,3 \%$. Semelhante ao horizonte $A$, a 
classe 0,125 milímetros foi a que menos contribuiu com a agregação desse horizonte, representando apenas $4,73 \%$.

Em profundidade, considerando os horizontes Bw1 e Bw2 do LB, foi observada a maior contribuição da classe de agregados 0,375 milímetros. Apesar dos percentuais dessa classe serem elevados em ambos os horizontes, o Bw2 apresentou 6,23\% a mais de agregados quando comparado com o Bw1. A classe 3 milímetros foi a segunda maior representativa do horizonte Bw1 com valores de 20,69\%, enquanto que no horizonte Bw2, a classe que ocupou essa posição foi a 6 milímetros, correspondendo a 17,05\%. O DMP do LB não apresentou variação significativa, isso porque os valores ficaram entre 0,55 e 0,80 milímetros, sendo o mínimo encontrado para o horizonte Bw1 e o máximo para o horizonte $\mathrm{AB}$.

O LV, com estrutura grau forte, tamanho médio a pequeno e tipo bloco angulares a subangulares (CARAMINAN et al., 2019) apresentou em seu horizonte A o predomínio da classe de 6 milímetros com valores de 54,47\%, seguida pela classe de 3 milímetros com valor de 25,86 \% (Figura 3). Situação semelhante foi verificada para os horizontes AB e Bw1 desse perfil. No caso do horizonte $A$, as classes de 6 e 3 milímetros tiveram expressividade em até $68,09 \%$, enquanto as demais classes foram responsáveis por $31,91 \%$ da agregação do perfil. Em contraste, os horizontes Bw2 e Bw3 apresentaram os menores percentuais relacionados à classe de 3 milímetros. Os valores foram de 35,32 e 35,79\%, respectivamente.

As classes menores do que 1,5 milímetros apresentaram os menores percentuais em todos os horizontes do perfil do solo, sendo que a classe de 1,5 milímetros ainda teve destaque na análise, com valor mínimo de 9,97 e máximo de 16,99\%. A classe menos representativa do LV foi a de 0,125 milímetros. Os percentuais dessa classe estiveram entre 0,54\% para o horizonte superficial A e 2,76\% para o horizonte em profundidade Bw3. No caso do DMP do LV, foi verificado 2,33 milímetros para horizonte superficial A enquanto que em profundidade houve diminuição considerável, alcançando 1,42 milímetros para o horizonte Bw3.

Ao comparar a distribuição das classes de agregados nos perfis dos Latossolos foi possível considerar que o LB apresenta maior variabilidade dos percentuais de agregação. Essa afirmação pode ser verificada ao observar os percentuais das classes de agregados do horizonte A frente aos valores dos demais horizontes desse solo. Neste perfil é possível constatar a presença das classes com maiores agregados nos horizontes superficiais (A e $A B)$ enquanto que em profundidade há uma diminuição dos agregados maiores e o aumento das classes dos menores agregados. No caso do LV, apesar de o horizonte superficial A apresentar os maiores valores da classe de 6 milímetros, é considerado que as classes de 6 
e 3 milímetros são as mais expressivas desde o topo até a base do perfil, indicando uma certa homogeneidade das classes de agregados nos horizontes que o constitui.

Figura 3 - Distribuição das classes de agregados no Latossolo Vermelho textura muito

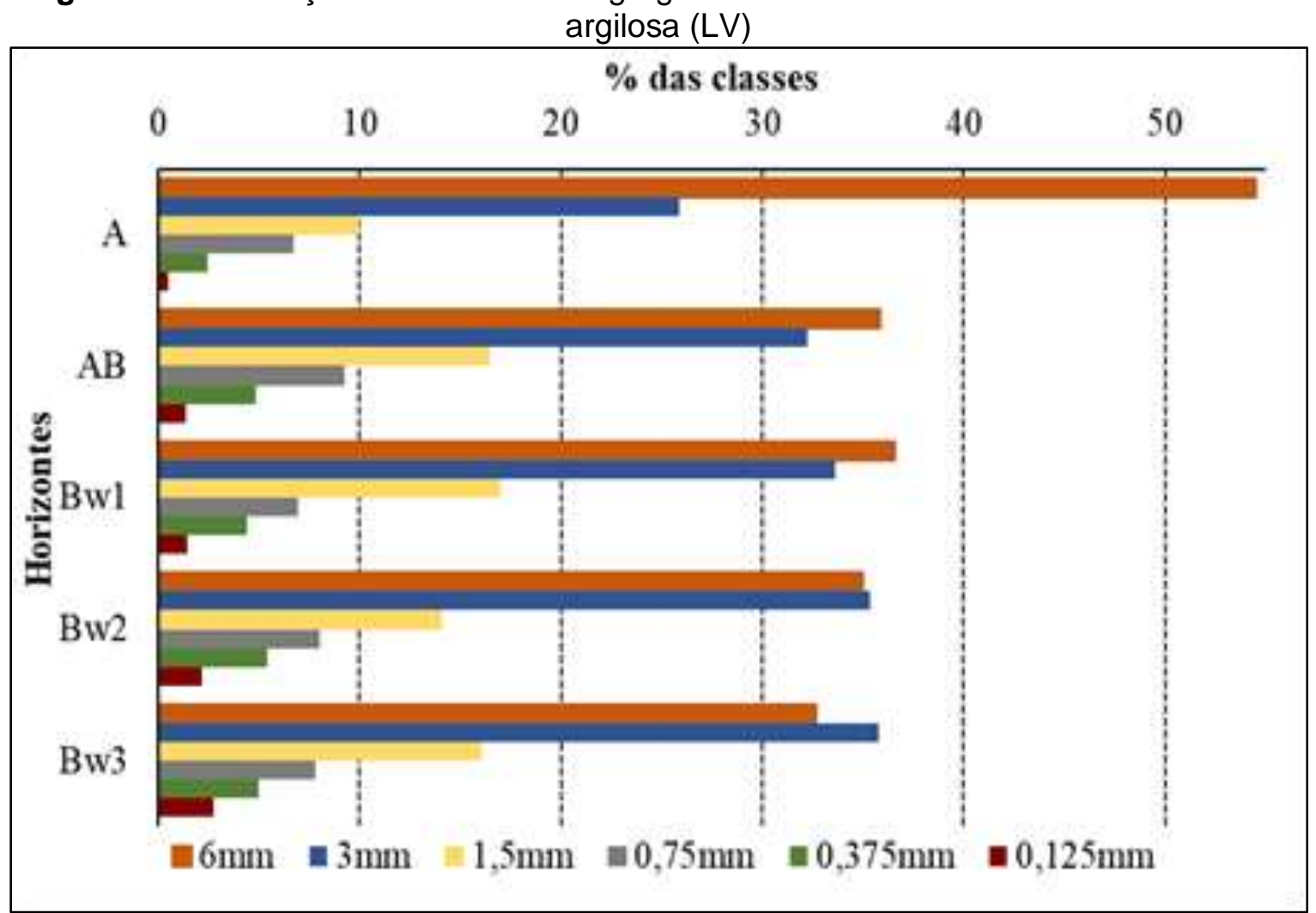

Fonte: os autores.

\section{Macro e Microagregados em Latossolos}

O LB apresentou o predomínio dos macroagregados em superfície enquanto que em profundidade houve a diminuição desta classe e aumento da classe dos microagregados (Figura 4A). Nos horizontes superficiais $A$ e $A B$ os valores percentuais da classe dos macroagregados foram 71,51 e 74,57\%, respectivamente. Em profundidade, esses valores tiveram redução de 14,45\% para o horizonte Bw1 e 22,96\% para o horizonte Bw2. Com a diminuição dos macroagregados, efeito inverso foi visualizado para a classe dos microagregados.

O LV é constituído principalmente por macroagregados, sendo que do topo até a base do perfil os percentuais estiveram acima dos 90\% (Figura 4B). O horizonte A apresentou os maiores valores percentuais dos macroagregados do perfil, chegando a $97,03 \%$, enquanto que os horizontes AB, Bw1, Bw2 e Bw3 apresentaram 93,83\%, 94,09\%, 92,39\% e 92,28\%, respectivamente. Em detrimento, a classe dos microagregados teve menor representatividade no perfil, com valores que ficaram abaixo dos $10 \%$. 
Figura 4 - Distribuição do percentual de agregados nos perfis dos Latossolos. A) Latossolo Bruno textura média (LB); B) Latossolo Vermelho textura muito argilosa (LV)

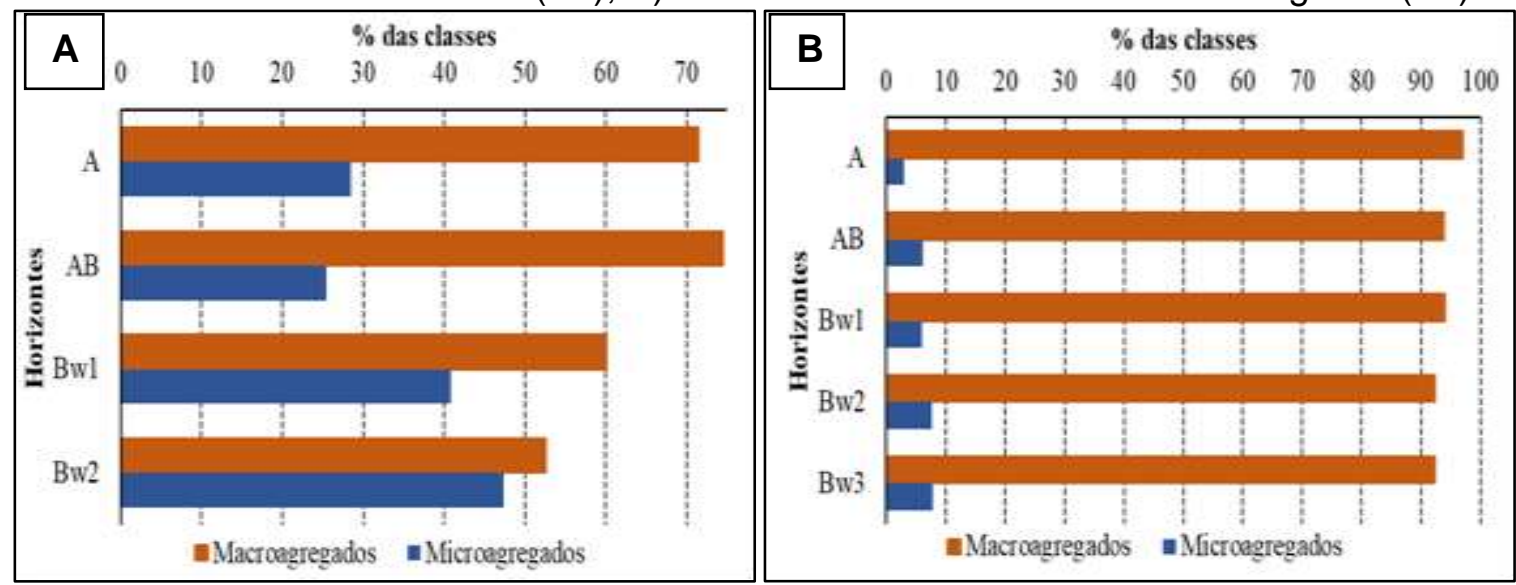

Fonte: os autores.

\section{Correlação entre macro e microagregados e teores de argila e carbono orgânico}

A classe dos macroagregados presente no LB apresentou correlação positiva fraca com o carbono orgânico (Figura 5A). Para a classe dos microagregados foi verificada correlação negativa moderada (Figura 5B). No primeiro caso, é possível considerar que o carbono orgânico colaborou pouco com a agregação dos macroagregados. No segundo caso, a correlação negativa evidenciou que com a diminuição do carbono orgânico do topo para a base do perfil houve o aumento da classe dos microagregados, indicando possivelmente que o carbono orgânico não colaborou efetivamente para a agregação dessa respectiva classe. Além disso, as correções verificadas não apresentaram significância a 95\% (valor-p <95\%).

A correlação entre a classe de macroagregados e a quantidade de argila neste perfil foi verificada como negativa muito forte (Figura $5 \mathrm{C}$ ). Neste caso, a presença de argila não contribuiu efetivamente para a agregação dos agregados maiores que 0,375 milímetros. Em contrapartida, os valores de argila contribuíram com a agregação dos agregados menores que 0,375 milímetros, isso porque foi verificada correlação positiva muito forte (Figura 5D) indicando que o aumento da quantidade de argila contribuiu para o aumento da classe dos microagregados pelo perfil.

No LV, a presença de carbono orgânico apresentou correlação positiva muito forte com a classe dos macroagregados (Figura 6A). A correlação positiva encontrada entre os macroagregados e a quantidade de carbono permitiu considerar que o carbono orgânico está contribuindo para agregação dessa classe. Por outro lado, a correlação entre a classe dos microagregados e o carbono orgânico foi negativa muito forte (Figura 6B). Neste caso, pode-se considerar que o carbono orgânico não está contribuindo diretamente para a 
agregação dos microagregados, possivelmente pela influência de outros atributos nos processos de formação e estabilização dos agregados.

Figura 5 - Dispersão entre a estabilidade de agregados, carbono orgânico e argila do Latossolo Bruno textura média (LB). A) Dispersão entre a classe dos macroagregados e o teor de carbono orgânico; B) Dispersão entre microagregados e carbono orgânico; C) Dispersão entre macroagregados e o teor de argila; D)

Dispersão entre microagregados e a argila

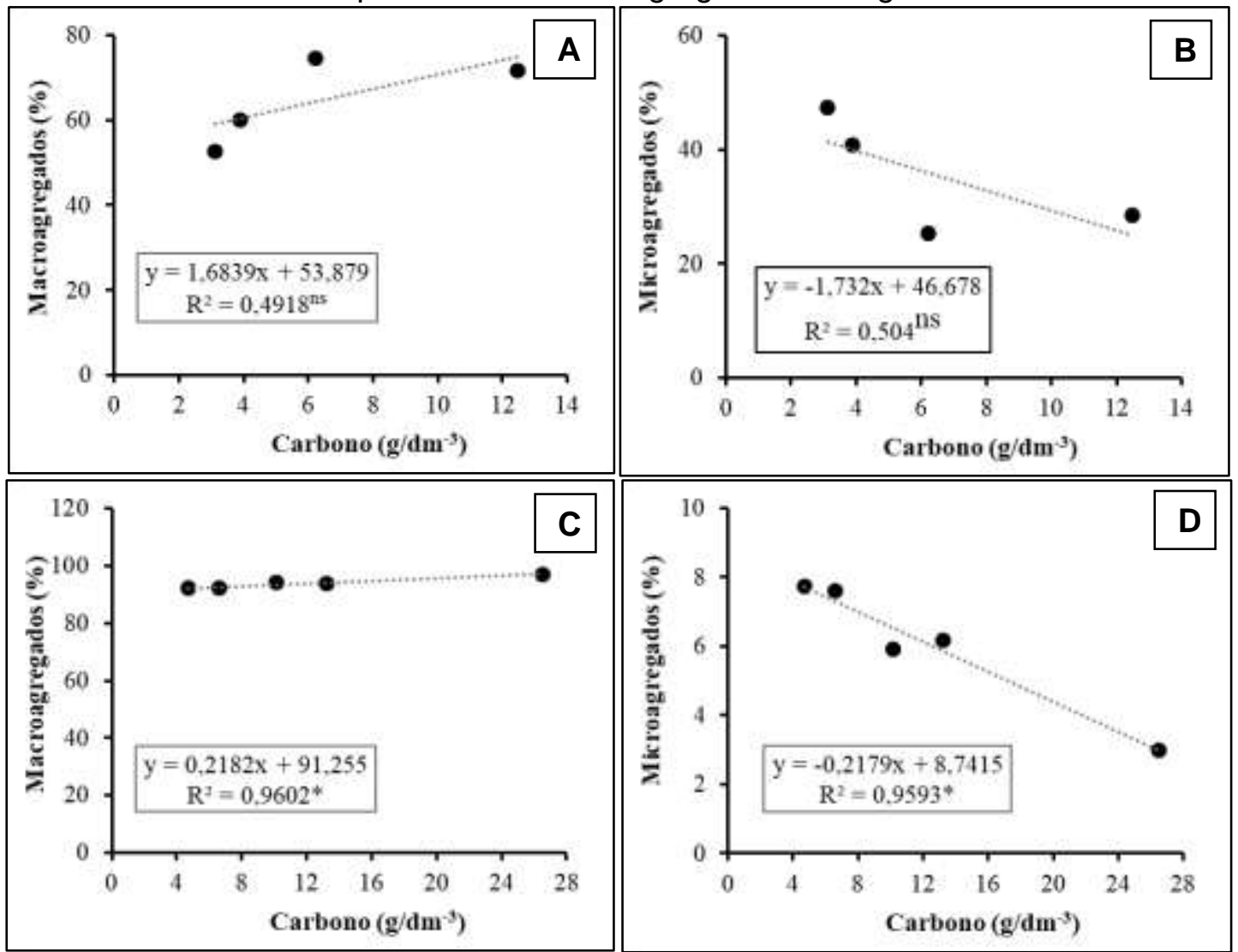

*significativo a $95 \%$ de confiança; ${ }^{\text {"s }}$ não significativo

Fonte: os autores.

A correlação entre a quantidade de argila e os macroagregados foi negativa moderada (Figura 6C). Já para a argila e a classe dos microagregados a correlação foi positiva moderada (Figura 6D). No entanto, esses valores não são significativos a 95\% (valor-p $<95 \%)$.

De maneira geral, foi verificado para os perfis dos Latossolos que a presença e quantidade de carbono orgânico pode estar influenciando diretamente o processo de formação e organização da classe dos macroagregados, enquanto que a presença de argila possivelmente está sendo responsável pela agregação dos microagregados. 
Figura 6 - Dispersão entre a estabilidade de agregados, carbono orgânico e argila do Latossolo Vermelho textura muito argilosa (LV). A) Dispersão entre a classe dos macroagregados e o teor de carbono orgânico; B) Dispersão entre microagregados

e carbono orgânico; C) Dispersão entre macroagregados e o teor de argila; C)

Dispersão entre microagregados e a argila
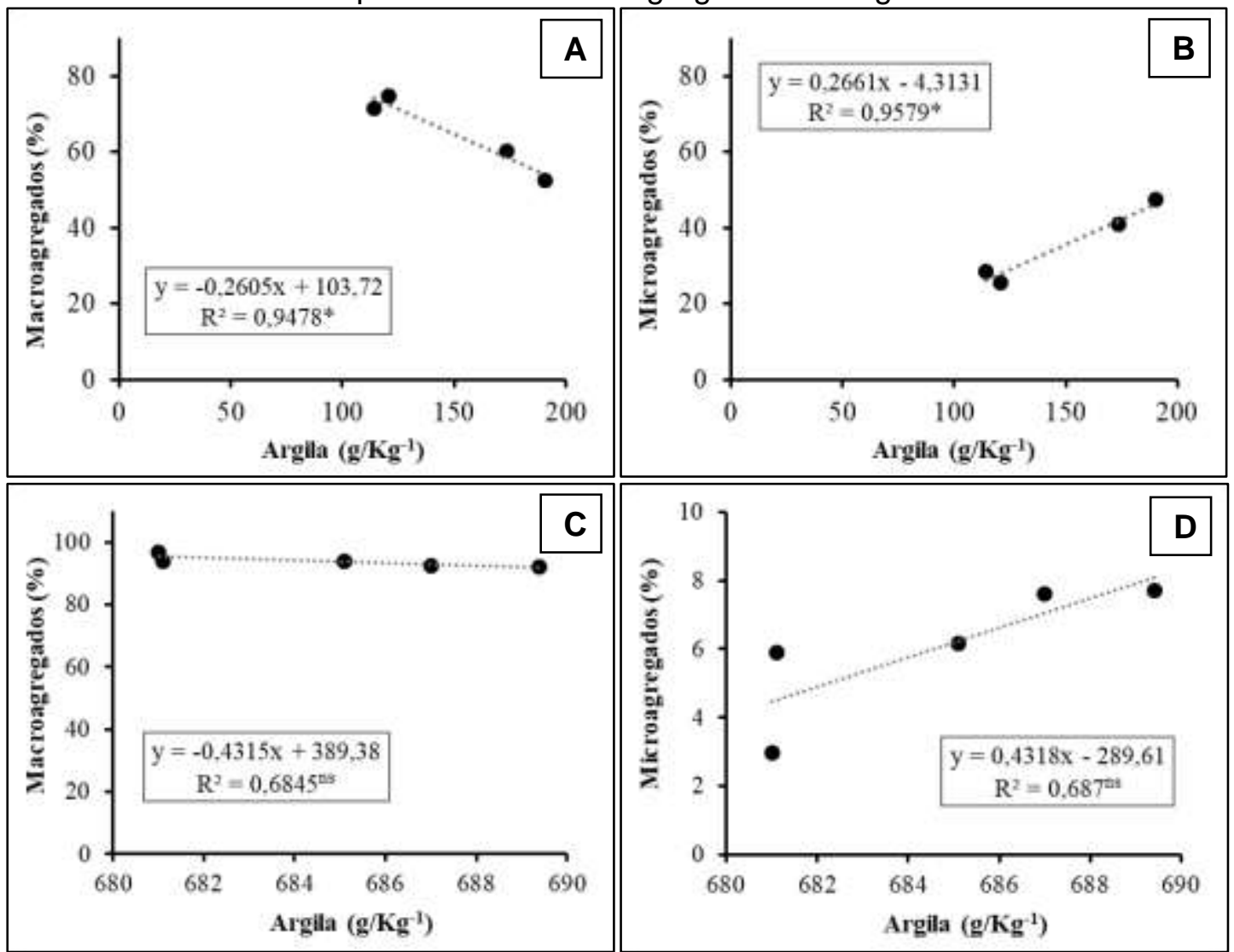

${ }^{*}$ significativo a $95 \%$ de confiança; ${ }^{\text {ns }}$ não significativo

Fonte: os autores.

\section{DISCUSSÃO}

Os resultados obtidos permitiram inferir que os Latossolos analisados possuem diferenças quanto à distribuição das classes dos agregados desde os horizontes superficiais até os horizontes profundos. O LB apresenta maior variabilidade dos percentuais das classes dos agregados ao longo do perfil quando comparado com o LB. Em especial, os horizontes superficiais ( $A$ e $A B$ ) de ambos os perfis apresentaram os maiores tamanhos de agregados, situação que está de acordo com os resultados obtidos por Terassi, Silveira e Bonifácio (2014). Os autores indicaram que provavelmente os agregados maiores encontrados nos horizontes superficiais estão associados à influência da matéria orgânica, fato que também está em concordância com as correlações obtidas entre os macroagregados e a quantidade de carbono orgânico dos perfis dos LB e LV.

Além da contribuição da matéria orgânica e do carbono orgânico, a formação de agregados maiores pode estar relacionada com o menor revolvimento dos horizontes 
superficiais nas áreas de remanescentes florestais (PEREIRA; THOMAZ, 2014). Além disso, a ação mecânica das raízes também colabora para a estabilização dos microagregados e formação de agregados maiores (BRONICK; LAL, 2005) e, portanto, os usos e manejos do solo podem interferir diretamente no tamanho dos agregados e sua estabilização (TISDALL; OADES, 1982). Outro aspecto também está associado à constituição mineralógica dos solos. Como apontado por Ferreira; Fernandes e Curi (1999), minerais como a caulinita e a gibbsita são recorrentes na estruturação do solo e manutenção dos agregados.

Se a quantidade de carbono orgânico é responsável pela agregação parcial dos macroagregados nos perfis de solos analisados, a diminuição desse elemento em profundidade pode interferir diretamente no aumento dos microagregados e consequentemente nos menores percentuais dos macroagregados, como foi observado nos perfis. Além do carbono orgânico, a constituição textural dos solos também é apontada como um fator que pode influenciar o tamanho dos agregados nos perfis estudados, bem como a variabilidade das classes. Como a textura do solo é herdada da intemperização do material parental do solo, Yang et al. (2020) apontam que a litologia é um fator que merece destaque na formação e estabilização dos agregados no solo. Apesar de os valores de argila e dos percentuais dos macroagregados apresentarem correlação negativa moderada, sugere-se que a presença dessa fração contribui indiretamente para a formação desses agregados.

Em consequência, acredita-se que as diferenças entre os percentuais das classes de macro e microagregados entre o LB e o LV possa ser explicado pelas diferenças texturais. $O$ primeiro perfil apresentou em média, 29,22\% a menos da classe dos macroagregados quando comparado com o segundo perfil. Da mesma forma, os valores do DMP desses perfis também apresentaram diferenças marcantes. Os menores valores foram encontrados no Latossolo Bruno textura média, apresentando, em média, $149,79 \mathrm{~g} / \mathrm{kg}^{-1}$ da fração argila, enquanto que os maiores valores do DMP foram obtidos no Latossolo Vermelho textura muito argilosa, que apresenta textura com $684,62 \mathrm{~g} / \mathrm{kg}^{-1}$ de argila (CARAMINAN et al., 2019). Situação semelhante foi verificada por Salton et al. (2008) que ao estudarem a agregação e a estabilidade de agregados em solos com texturas distintas e em sistemas de manejos diferentes, observaram o efeito do teor de argila na agregação, com destaque para os maiores valores do DMP em um solo contendo $540 \mathrm{~g} / \mathrm{kg}^{-1}$ de argila e os menores valores para o solo com $360 \mathrm{~g} / \mathrm{kg}^{-1}$ de argila.

Em geral, a análise dos resultados permite inferir sobre a estabilidade de agregados de Latossolos com texturas média e muito argilosa em remanescentes florestais, não somente para os horizontes superficiais, mas também em profundidade. Conhecer e compreender a agregação dos solos em condição natural é essencial para prever futuros 
impactos nesses sistemas, que de forma indireta também impactam os demais elementos dos geossistemas.

\section{CONCLUSÕES}

Os perfis de Latossolos com texturas diferentes e em áreas remanescentes da Floresta Estacional Semidecidual apresentam os maiores percentuais das classes de agregados com tamanhos de seis e três milímetros. Em geral, verificou-se que os efeitos da argila e do carbono orgânico sobre o DMP manifestaram-se de forma diferenciada conforme a profundidade dos perfis. No caso do perfil do LB, observa-se influência significativa da argila na agregação dos microagregados, enquanto que o carbono orgânico pouco contribui para a formação dos macroagregados. Em relação ao perfil do LV, ocorreu situação inversa, ao ponto que o carbono orgânico está influenciando de forma mais efetiva na macroagregação, ao mesmo tempo em que a argila apresentou menor influência na microagregação, possivelmente, em função de outros agentes agregadores.

\section{REFERÊNCIAS}

ALMEIDA, Risely Ferraz et al. Correlação do tamanho e da distribuição dos agregados em latossolos amarelo da região do Triângulo Mineiro com diferentes ambientes. Bioscience Journal, Uberlândia, MG, v. 3, n. 5, p. 1325-1334, 2014.

BRONICK, C. J.; LAL, Rattan. Soil structure and management: a review. Geoderma: an International Journal of Soil Science, Amsterdam, NL, v. 124, p. 3-22, 2005.

CAMARGO, Otávio Antonio de. Métodos de análise química, mineralógica e física de solos. Campinas: IAC, 1986.

CARAMINAN, Laine Minele et al. Descrição macromorfológica e granulométrica de dois perfis de solos no estado do Paraná. In: ENCONTRO INTERNACIONAL DE PRODUÇÃO CIENTÍFICA - EPCC, 11., 2019, Maringá, PR. Anais [...]. Maringá: Unicesumar, 2019. p. 110.

CASTRO FILHO, Celso D.; MUZILLI, Osmar; PODANOSCHI, A. L. Estabilidade dos agregados e sua relação com o teor de carbono orgânico num Latossolo roxo distrófico, em função de sistemas de plantio, rotações de culturas e métodos de preparo das amostras.

Revista Brasileira de Ciência do Solo, Viçosa, MG, v. 22, n. 3, p. 527-538, 1998.

CHESWORTH, Ward. Encyclopedia of soil science. Amsterdam, Netherlands: Springer, 2008.

COUTINHO, Leopoldo Magno. Biomas brasileiros. São Paulo: Oficina de textos, 2016.

CRUZ, A. C. R.; PAULETTO, E. A.; FLORES, C. A.; SILVA, J. B. Atributos físicos e carbono orgânico de um argissolo vermelho sob sistemas de manejo. Revista Brasileira de Ciência do Solo, Viçosa, MG, v. 27, n. 6, p. 1105-1112, 2003.

FERREIRA, Fernando Perobelli et al. Carbono orgânico, óxidos de ferro e distribuição de agregados em dois solos derivados de basalto no Rio Grande do Sul - Brasil. Ciência Rural, Santa Maria, RS, v. 37, n. 2, p. 381-388, 2007. 
FERREIRA, Mozart Martins; FERNANDES, B.; CURI, Nilton. Mineralogia da fração argila e estrutura de Latossolos da região sudeste do Brasil. Revista Brasileira de Ciência do Solo, Viçosa, MG, v. 23, p. 507-514, 1999.

FILIZOLA, Heloisa Ferreira; BARRETO LUIZ, Alfredo José. Tempo de cultivo contínuo de cana-de-açúcar e influencias nas características físicas e carbono orgânico de Latossolos Vermelhos Distróficos em Guaíra/SP. Revista de Estudos Ambientais, Blumenau, SC, v. 20, n. 2, p. 21-36, 2018.

GASPARETTO, Nelson Vicente Lovatto. As formações superficiais do Noroeste do Paraná e sua relação com o Arenito Caiuá. 1999. Tese (Doutorado em Geociências) Instituto de Geociências, Universidade de São Paulo, São Paulo, SP, 1999.

IBGE. Manual técnico de vegetação brasileira. Rio de Janeiro: IBGE, 2012.

LAL, Rattan; SHUKLA, Mritunjay Kumar. Principles of soil physics. Ohio, USA: The Ohio University Columbus, 2004.

LARACH, Jorge Olmos Iturri et al. Levantamento de reconhecimento dos solos do Estado do Paraná. Londrina: IAPAR, 1984.

LEPSCH, Igo F. 19 lições de pedologia. São Paulo: Oficina de Textos, 2011.

MENON, Manoj et al. Pore system characteristics of soil aggregates and their relevance to aggregate stability. Geoderma: an International Journal of Soil Science, Amsterdam, NL, v. 366, e114259, 2020.

MINEROPAR. Atlas geológico do Estado do Paraná. Curitiba: MINEROPAR, 2001.

MINEROPAR. Atlas geomorfológico do Estado do Paraná. Curitiba: Universidade Federal Do Paraná, 2006.

NARDY, Antonio José Ranalli et al. Geologia e estratigrafia da formação serra geral.

Geociências, São Paulo, v. 21, n. 1-2, p. 15-32, 2002.

PEREIRA, Adalberto Alves; THOMAZ, Edivaldo Lopes. Estabilidade de agregados em diferentes sistemas de uso e manejo no município de Reserva- PR. Revista Brasileira de Geografia Física, Recife, PE, v. 7, n. 2, p. 378-387, 2014.

SALTON, Júlio Cesar et al. Agregação e estabilidade de agregados do solo em sistemas agropecuários em Mato Grosso do Sul. Revista Brasileira de Ciência do Solo, Viçosa, $M G$, v. 32, p. 11-21, 2008.

SALTON, Júlio Cesar et al. Agregação do solo e estabilidade de agregados. In: TEIXEIRA, Paulo Cesar et al. (eds.). Manual de métodos de análise de solo. Brasília, DF: Embrapa, 2017. p. 129-138.

SANTOS, Raphael David dos et al. Manual de descrição e coleta de solo no campo. 7. ed. rev. e ampliada. Viçosa, MG: Sociedade Brasileira de Ciência do Solo, 2015.

SCHAETZL, Randall; ANDERSON, Sharon. Soil genesis and geomorphology. New York: Cambridge University Press, 2005.

SILVA, Flavio de Paula e; KIANG, Chang Hung; CHANG, Maria Rita Caetano. Estratigrafia de subsuperfície do Grupo Bauru (K) no Estado de São Paulo. Revista Brasileira de Geociências, São Paulo, SP, v. 35, p. 77-88, 2005.

SILVA, I. F.; MIELNICZUK. João. Sistemas de cultivo e características do solo afetando a estabilidade de agregados. Revista Brasileira de Ciência do Solo, Viçosa, MG, v. 22, p. 311-317, 1998.

TABOADA, Miguel Angel et al. Mechanisms of aggregation in a silty loam under different simulated management regimes. Geoderma: an International Journal of Soil Science, Amsterdam, NL, v. 123, n. 3-4, p. 233-244, 2004. 
TERASSI, Paulo Miguel de Bodas; SILVEIRA, Helio. Aplicação de sistemas de classificação climática para a bacia hidrográfica do rio Pirapó - PR. Formação (Online), Presidente Prudente, SP, v. 1, n. 20, p.111-128, 2013. DOI: https://doi.org/10.33081/formacao.v1i20.2058.

TERASSI, Paulo Miguel de Bodas; SILVEIRA, Helio; BONIFÁCIO, Cássia Maria. Variação da estabilidade de agregados e suas relações com a vulnerabilidade dos solos ao longo de uma vertente na região noroeste do Paraná. Boletim de Geografia, Maringá, PR, v. 32, n. 1, p. 166-176, 2014.

TISDALL, Judith M.; OADES, Jennifer Malcolm. Organic matter and water-stable aggregates in soils. The Journal of Soil Science, Oxford, Inglaterra, GB, v. 33, n. 2, p. 141-163, 1982.

WHITE, Robert E. Principles and practice of soil Science: the soil as a natural resource. Oxford: Blackwell Publishing, 2006.

YANG, Songyu et al. Lithology - and climate-controlled soil aggregate-size distribution and organic carbon stability in the Peruvian Andes. Soil, Göttingen, LS, v. 6, n. 1, p. 1-5, 2020.

ZENG, Quanchao et al. Soil aggregate stability under different rain conditions for three vegetation types on the Loess Plateau (China). Catena, Amsterdam, NL, v. 167, p. 276-283, 2018.

\section{AGRADECIMENTOS}

À Fundação Araucária por financiar parte da pesquisa, ademais, o presente trabalho foi realizado com apoio da Coordenação de Aperfeiçoamento de Pessoal de Nível Superior Brasil (CAPES) - Código de Financiamento 001.

Recebido: maio de 2020. Aceito: setembro de 2020. 